\section{Cardiac Troponin T}

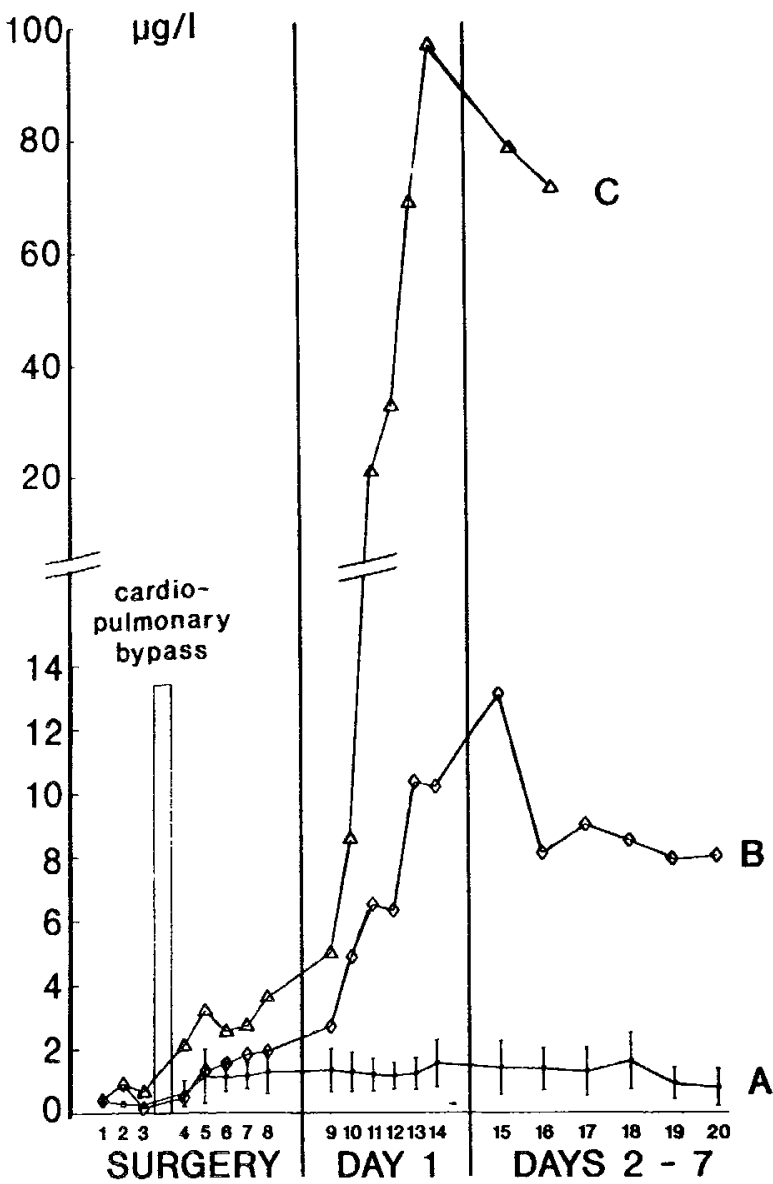

Cardiac troponin $\mathrm{T}$ concentrations before, during, and after CABG.

(A) = patients without perioperative myocardial infarction (mean and SD) (B) and (C) = intraoperative myocardial infarction (patient $C$ died from cardiogenic shock)

concentrations before bypass $(1.26[0.67]$ vs $0.24[0.08] \mu \mathrm{g} / \mathrm{l}$; $\mathrm{p}<0.05$ ). In 2 patients with intraoperative myocardial infarction troponin $T$ concentrations were much increased (figure). 1 died from cardiogenic shock on day $3(\mathrm{C}$, see figure). Two other patients who did not meet criteria for myocardial infarction showed moderately increased troponin $T$ concentrations $(5.9$ and $3-5 \mu \mathrm{g} / 1$ at peak). Only 1 of these patients had borderline CK-MB activities after reperfusion, but none had new ECG abnormalities after CABG.

We conclude that cardiac troponin ' $T$ reliably identifies perioperative myocardial infarction during CABG. Concentrations below $2.5 \mu \mathrm{g} / 1$ rule out clinically relevant myocardial injury. The significant increase in cardiac troponin $T$ after reperfusion in patients with uncomplicated outcome probably reflects myocardial cell damage from ischaemia during cardioplegia. Whether the peak concentrations of 5.9 and $3.5 \mu \mathrm{g} / 1$ in 2 patients not classified as having myocardial infarction reflect microinfarcts missed by ECG and $\mathrm{CK}-\mathrm{MB}$ activity remains to be elucidated.

\section{J. MAIr \\ CH. WIESER \\ I. SEIBT}

Departments of Medical Chemistry and Biochemistry,

Anaesthesia and Intensive Care,

E. ARTNER-DWORZAK

and Cardiac Surgery,

W. FurTWÄNGLER

University of Innsbruck

A-6020 innsbruck, Austria

F. WALDENBERGER

D. BALOGH

B. Puschendorf

1. Force $T$, Hibberd $P$, Wecks $G$, et al. Perioperative myocardial infarction after coronary artery bypass surgery. Circulation 1990; 82: 903-12.

2 Kanus HA, Remppis A, Looser S, Haliermeier K, Scheffold T, Kübler W. Enzyme linked immuno assay of cardiac troponin $\mathrm{t}$ for the detection of acute myocardial infarctoon in parients. $7 \mathrm{Mol} \mathrm{Cell} \mathrm{Cardiol} \mathrm{1989;} \mathrm{21:} 1349-53$

3 Le TH, Goldman L. Serum enzyme assays in the diagnosis of acure myocardial infarction. Amn Intern Med 1986; 105: 221-33.

\section{Breast milk and necrotising enterocolitis}

SIR,-Dr Lucas and Dr Coles' report (Dec 22, p 1519) is timely and gave much needed information about the role of breast milk in the prevention of necrotising enterocolitis (NEC). They also point out that breast milk is a scarce resource in neonatal units. The other feature of their results is that the main benefit of breast milk is seen in the more mature infants. Analysis of their table $\mathrm{V}$ shows that, for both total cases and confirmed cases, breast milk supplements produce no statistically significant advantage over formula in infants from 25 to 30 weeks' gestation and only a modest improvement in the risk ratio but highly significant and clinically increasing benefits in more mature infants. This pattern of response has two important corollaries.

The first is that difficulties of formula feeding are unlikely to lie in the composition of the major nutrients-for example, the caseine/ whey ratio. If this were the cause of a higher incidence of NEC in premature infants fed such formula, then the effect should be most obvious in the smallest infants whose intestinal mucosa is least mature. Alternatively breast milk might contain a factor that stimulates a protective response in the intestine of more mature infants, but not in the very premature infant.

The second corollary is in the selection of infants to receive breast milk as a protection against NEC. The limited supply of breast milk should be used where it can do the most good. The table is derived from Lucas and Cole's table v, and shows, for all cases of NEC, the benefit of breast milk by gestational age, expressed as reduction of incidence of NEC and the number of lives saved.

EFFECT OF BREAST MILK SUPPLEMENTS ON INCIDENCE OF CLINICAL NEC AND CONSEQUENT DEATH

\begin{tabular}{c|c|c|c|c}
\hline \multirow{2}{*}{$\begin{array}{c}\text { Gestational } \\
\text { age (wk) }\end{array}$} & \multicolumn{2}{|c|}{$\begin{array}{c}\text { Expected } \\
\text { incidence of NEC }\end{array}$} & $\begin{array}{c}\text { No of cases } \\
\text { of NEC } \\
\text { prevented with } \\
\text { breast milk }\end{array}$ & $\begin{array}{c}\text { No of deaths } \\
\text { prevented }\end{array}$ \\
\hline $25-27$ & 157 & 200 & 43 & $25 \dagger$ \\
$28-30$ & 48 & 84 & 36 & 33 \\
$31-33$ & 11 & 80 & 69 & 61 \\
$34-36$ & 0 & 93 & 93 & 92 \\
\hline
\end{tabular}

*Per 1000 infants fed.

tIn calculation of deaths prevented, allowance is made for deaths from other causes.

The reduction in incidence of NEC and in resultant mortality varies with the maturity of the infants. The number of lives saved rises steadily with gestational age at birth. If breast milk is a limiting resource then it should be given by choice to more mature infants who are more likely to benefit. However, there are many such infants and some selection is necessary, so the use of banked breast milk supplements should be given first, in the absence of milk from the mother, to those infants who need enteral feeding.

Human Nutrition Research Group.

Department of Child Health,

University of Queensland.

St Lucia Q 4067, Australı

A. E. Dugdale

SIR,-Necrotising enterocolitis (NEC) remains a matter of great concern, and Dr Lucas and Dr Cole show that, with a reduced intake of breast milk, the incidence of NEC could increase. Human milk banks do not exist in the Netherlands, and although breast feeding is supported in our hospital few mothers of very-lowbirthweight (VLBW) infants supply breast milk for their babies. Psychological stress and the fact that these mothers are recovering from pregnancy disorders such as pre-eclampsia contribute to this. Nevertheless, the incidence of NEC in our neonatal intensive care unit has been very low over the past 7 years. ${ }^{1}$

Last year 149 VI.BW infants were admitted (birthweight 1100 [SD 240] g, gestational age at birth 29.3 [26] weeks) and $18.2 \%$ died. 4 showed grade $1 \mathrm{NEC}^{2}$ and 2 grade $2 ; 1$ of these 6 infants died at age 3 days, when no enteral feeding had been given, so prenatal factors may have played a part. Some years ago, our feeding policy for VLBW was changed to one of delayed enteral 
feeding. ${ }^{1}$ All VLBW infants received intravenous feeding only up to 7 days of age. Thereafter enteral feeding with a preterm formula (Nenatal') was introduced with supplements of intravenous feeding up to $150 \mathrm{ml} / \mathrm{kg}$ daily:

$\begin{array}{cccc}\text { Day } & \text { Enteral feeding } & \text { Dilution } & \begin{array}{c}\text { Amount } \\ \text { (m//kg per day) }\end{array} \\ 8 & \text { Nenatal: glucose 5\% } & 1: 1 & 20 \\ 9 & & & 40 \\ 10 & & & 60 \\ 11 & \text { Nenatal: glucose 5\% } & 3: 1 & 60 \\ 12 & & & 80 \\ 13 & & \text { Undiluted } & 100 \\ 14 & \text { Nenatal } & & 100 \\ 15 & & & 120 \\ 16 & & & 150 \\ 17 & & & 150\end{array}$

Before the start of enteral food intake, venous and low position arterial umbilical lines were removed, and catheters were placed in peripheral arteries and veins. With this regimen the incidence of NEC in our VLBW population has been low for many years. We agree with Lucas and Cole that breast milk may prevent NEC but would not wish to stress the mothers of these sometimes very ill babies further by forcing them to supply breast milk. Our results show that the incidence of neonatal NEC can be low when preterm formula is used. Whenever breast milk is not available we recommend delayed introduction of diluted enteral feeding in VLBW infants to prevent NEC.

\section{Department of Paediatrics,}

Subdivision of Neonatology,

Sophı Chıldren's Hospital/Academıc Hospıtal.

3038 GE Rotterdam, Netherlands

1. Spritzer R, Koolen AMP, Baerts W, Fetter WPF, Lafeber HN, Sauer PJJ. A prolonged decline in the incidence of necrotzing enterocolitss after the introduction of a cautious feeding regimen. Acta Paediatr Scand 1988; 77: 909-11

2. Britush Assocation for Pennatal Pediatrics and the Public Health Laboratory Service Communicable Disease Surveillance Centre. Surveillance of necrotusing enterocolitis, 1981-1982. Br Med J 1983; 287: 824-26.

\section{Captopril-induced IgA deficiency}

SIR,-IgA deficiency is the most common form of primary immunodeficiency, with a prevalence of 1 in 600 in a normal population. The deficiency is often associated with sinopulmonary or gastrointestinal infections. Drugs, including penicillamine, ${ }^{1-3}$ phenytoin, sulphasalazine, gold salts, and diclofenac have been shown to induce reversible or permanent IgA deficiency. Since the aetiology of IgA deficiency is unknown, the study of drug-induced cases is of considerable interest since it may throw light on the molecular basis of the disorder.

Penicillamine contains a highly reactive sulphydryl group, which has been implicated in the pathogenesis of drug-induced IgA deficiency. ${ }^{4}$ Captopril also has a sulphydryl group and it has been successful in patients with rheumatoid arthritis. ${ }^{5}$ Captopril has been

TIME COURSE OF CAPTOPRIL-INDUCED IgA DEFICIENCY

\begin{tabular}{l|c|c|c}
\hline \multicolumn{1}{c|}{ Date } & $\lg M(\mathrm{~g} / \mathrm{l})$ & $\operatorname{lgG}(\mathrm{g} / \mathrm{l})$ & $\operatorname{lgA}(\mathrm{g} / \mathrm{l})$ \\
\hline March 11, 1986 & $0 \cdot 8$ & $7 \cdot 5$ & $1 \cdot 6$ \\
March 22 & $1 \cdot 4$ & $13 \cdot 0$ & $1 \cdot 6$ \\
Oct 8 & $0 \cdot 6$ & $12 \cdot 5$ & $0 \cdot 03$ \\
April 8, 1987 & $0 \cdot 4$ & $8 \cdot 4$ & $<0 \cdot 01$ \\
Nov 12 & $0 \cdot 5$ & $7 \cdot 1$ & $<0 \cdot 01$ \\
March 21, 1988 & $0 \cdot 3$ & $7 \cdot 0$ & $<0 \cdot 01$ \\
June 9 & $1 \cdot 6$ & $6 \cdot 5$ & $0 \cdot 08$ \\
July 7 & $1 \cdot 8$ & $7 \cdot 5$ & $0 \cdot 09$ \\
Aug 4 & $2 \cdot 8$ & 10.2 & $0 \cdot 16$ \\
Nov 10 & $2 \cdot 3$ & $10 \cdot 7$ & $0 \cdot 18$ \\
April 11, 1989 & $1 \cdot 1$ & $9 \cdot 8$ & $0 \cdot 20$ \\
June 15 & $2 \cdot 0$ & $15 \cdot 0$ & 0.4 \\
Feb 8, 1990 & $1 \cdot 0$ & $11 \cdot 3$ & $0 \cdot 5$ \\
May 17 & $1 \cdot 1$ & $11 \cdot 9$ & $0 \cdot 6$ \\
Nov 1 & $1 \cdot 1$ & $12 \cdot 7$ & $0 \cdot 9$ \\
\hline
\end{tabular}

Captopril treatment began on March 11, 1986, and was stopped at transplant on May 5, 1988. Treatment with propanolol, frusemide, and prednisolone was contınued after transplant.

suspected but not proved to be associated with immunoglobulin deficiency. ${ }^{6} \mathrm{We}$ report a case strongly associating captopril with IgA deficiency.

A 10-year-old girl with hypertension due to glomerulonephritis was on long-term propranolol, frusemide, and prednisolone. In March, 1986, captopril was added $(6.25 \mathrm{mg}$ daily, increasing to $18.75 \mathrm{mg}$ in June, 1986). Serum IgA levels fell after half a year of this treatment and were not detectable within a year (table). Levels of IgG subclasses remained normal throughout (not shown). In May, 1988, the patient received a kidney graft and captopril was discontinued. The serum IgA slowly rose to normal (table).

Captopril interacts with the immune system by inducing a hypersensitivity response or by disruption of immune regulation including the formation of immune complexes ${ }^{7}$ and autoantibodies. ${ }^{8}$ This dysregulation seems also to affect IgAproducing cells selectively, resulting, in rare cases, in the induction of IgA deficiency. The chemical similarity between the two drugs and the observation that both induce a similar pattern of immunological disorder (systemic lupus, pemphigus, and IgA deficiency) make it likely that the mechanism responsible for penicillamine-induced side-effects is also responsible for the adverse events induced by captopril.

Department of Clinical Immunology

Huddinge Hospital,

LENNART HAMMARSTROM

S-14186 Huddinge, Sweden

C. I. EDVARD SMITH

Department of Paediatrics,

Huddinge Hospital

ULLA BERG

1. Proesmans W, Jaeken J, Eeckels R. D-penıllamıne-induced IgA deficiency in. Wilson's disease. Lancet 1976; ii: 804-05.

2. Hjalmarson $\mathrm{O}$, Hanson L-Ä, Nilsson L-Ä. IgA deficiency durng D-penccllamune treatment. $\mathrm{Br}$ Med $\mathcal{1} 1977,1.549$.

3. Stanworth DR, Johns $P$, Williamson N, Shadforth $M$, Felix-Davies D, Thompson R Drug-induced IgA deficiency in rheumatold arthrit1s. Lancet 1977; 1 1001-02

4. Smith CIE, Hammarstrom L. Immunologic abnormalites induced by D-penicillamine. In: PAR (pseudo-allergic reactions), vol IV: involvement of drugs and chemicals. Basel: Karger, 1985: 138-80.

5. Martin MFR, Surrall K, McKenna F, Dixon JS, Bird HA, Wright V. Captopril d new long-term agent for treating rheumatoid arthrits. Arm Rheum Dis 1983, 42: 231

6. Suzuki T, Okada J, Kashiwasaki S Selective IgA deficiency developed durng treatment of scleroderma k1dney with captopril. $f$ Rheumatol 1988; 15: 716-17

7. Hoorntye SJ, Kallenberg CGM, Weening JJ, Donker AJM, The TH, Hoedemaeker PJ Immune complex glomerulopathy in patıents treated with captopril Lanut 1980, i: 1212

8. Kallenberg CGM, Hoorntje SJ, Smit AJ, et al Antinuclear and antuature DNA antibodies during captopril treatment. Acta Med Scand 1982; 211: 297

\section{Thalidomide hypersensitivity in AIDS}

SIR,-Treatment of severe aphthous oropharyngeal ulceration with thalidomide has been described in patients with symptomatic HIV infection by several groups. ${ }^{12}$ We have also seen rapid alleviation of symptoms with this drug. However, we now report that some patients have a hypersensitivity reaction that requires discontinuation of therapy. We are not aware that this has been reported before.

8 male patients with Centers for Disease Control stage IV HIV infection presented with severe oropharyngeal aphthous ulceration. In 7 patients, one or two large ulcers had developed in the tonsillar region of the oropharynx $(n=5)$, alveolar ridge $(n=1)$, and base of tongue ( $n=1$ ) causing severe pain and/or dysphagia over a period of between one and twelve weeks. The eighth patient had had recurrent multiple small oral aphthae over fifteen months but then presented with a six-week history of persistent ulceration resistant to topical treatment. Herpes simplex virus cultures were negative in all patients and histological examination in 3 showed non-specific inflammation and ulceration with no evidence of cytomegalovirus inclusion bodies or malignant disease.

Previous therapies in 7 patients had failed. Thalidomide ( $200 \mathrm{mg} /$ day in 7 patients and $100 \mathrm{mg} /$ day in 1 ) was begun and led to rapid relief of pain with partial or complete healing in 7 . In 1 patient the dose was halved $(100 \mathrm{mg})$ after three days because of drowsiness In a further 3 patients thalidomide was stopped early (six to twelve days) because of a widespread erythematous macular rash Rechallenge was undertaken in 2 of these 3 patients because of recurrence of pain and ulceration. Hypersensitivity reactions (ferer. 